\title{
Five years of the Journal of Transport and Health
}

Professor Jennifer S Mindell

\section{j.mindell@ucl.ac.uk}

Health \& Social Surveys Research Group

Dept Epidemiology \& Public Health

$\mathrm{UCL}$

1-19 Torrington Place

London WC1E 6BT

Tel +44-20-7679-1269

This volume marks the completion of five years of publication of the Journal of Transport and Health. I should like to thank the authors, reviewers, board members, guest editors, and particularly the associate editors and the team at Elsevier for their support of the journal since the first issue was published in March 2014. We have achieved a very respectable set of metrics for a new journal in a niche field that is becoming widely recognised as important, with increasing numbers of academics, practitioners and policy-makers working across disciplinary boundaries. The Transport and Health Science Group (THSG), formerly the Transport and Health Study Group (Watkins, 2014) now has a Latin American branch. The International Professional Association for Transport and Health (IPATH, https://www.tphlink.com/ipath.html) is increasing its collaborative work with other professional organisations, particularly in the USA.

Transport and health as a research area has progressed from descriptive studies to assessment of interventions. A number of methodological issues are highlighted in this issue. Researchers should note that walking may be underestimated by self-report compared with GPS measurement (Hong et al, 2018). The authors ascribe this to the difficulty in recalling short walks. Mackie and colleagues (2018, this issue) discuss difficulties in the interplay between local government, researchers, and residents when retrofitting existing streets. Shekarrizfard and colleagues (2018, this issue) compare different methods for modelling air pollution in their study using breast and prostate cancer as the outcomes.

In many cases, the interventions being evaluated are natural experiments (Craig, 2012). Bristol City Council, in England, has introduced a city-wide $20 \mathrm{mph}$ (32kph) speed limit using signage alone, phasing it in to cover more roads over time. This enabled Bornioli et al (2018, Editor's Choice) to use a step-wedge design (Brown \& Lilford, 2006) in their evaluation, reported in this volume: they found reductions in both the mean speed and the $85^{\text {th }}$ centile. Mackie et al (2018) report on co-production of research, including co-design, with local communities to redesign the streets using the concept of 'self-explaining roads'. The new designs improved facilities for walking and cycling and included infrastructure designed to slow motor vehicle speeds. Turner and colleagues (2018) have produced a 
programme theory to underpin their ongoing evaluation of the health impacts of area-wide $20 \mathrm{mph}$ speed limits.

It is important to understand what works to increase active travel. Knowing the [short] distance or time needed to reach a destination, as well as being confident the route can be followed easily, increases the likelihood of walking. In central London, Transport for London provided signage pointing out the time to walk to neighbouring stations, to encourage people to walk instead of using the tube [metro] - albeit the initial motivation was to reduce overcrowding on the trains (Cross River Partnership, 2018). Kellikoa and colleagues report in this issue that pedestrians and cyclists in Hawai'i felt that wayfinding signage was beneficial for them and for others (Keliikoa et al, 2018).

Other aspects of modern life may reduce active travel. Hong et al (2018, this issue) have shown that greater use of internet-based social networking services is associated both with less walking (using objective measurements) and with increased obesity (based on self-reported height and weight) in adults. Perceived safety risks from crime and traffic are potent deterrents for active travel (Appleyard \& Ferrell, 2017; Evers et al, 2014; Foster et al, 2013; Rothman et al, 2015) and for allowing children to travel unescorted (Hillman, 1990). O'Toole and Christie (2018, this issue) report that although the social inequalities found in their study were less extreme than in earlier studies, children who lived in the most deprived areas had pedestrian fatality rates per 1000 population almost three times as high as their peers in the most affluent areas. These differences persisted after adjusting for age- and sex-specific travel distances by mode. For boys, there were also marked increases in cycle fatalities in those who lived in more deprived areas.

Adverse weather conditions can also impede safe walking. Nordic countries see increased falls due to icy conditions (Gao et al, 2004). The direct costs of such falls are higher than those for road travel injuries, as currently defined (reported by Gard et al, 2018, in this issue), adding to the rationale for including pedestrian falls within the definition of road travel injuries (Methorst et al, 2017a and 2017b). Gard et al (2018) identified that devices that aid balance as well as increasing friction are important for reducing slips.

Finally, please note that the deadline for submissions for the special issue on transport and health in Latin American countries is $31^{\text {st }}$ December 2018. Read the scope of the call here:

https://www.journals.elsevier.com/journal-of-transport-and-health/call-for-papers/call-for-paperstransportation-health-latin-america.

\section{Funding}

No funding was received for this editorial.

Conflict of interest.

There are no conflicts of interest

\section{References}

Bornioli A, Bray I, Pilkington P, Bird EL. 2018 The effectiveness of a 20 mph speed limit intervention on vehicle speeds in Bristol, UK: A non-randomised stepped wedge design. Journal of Transport \& Health, Volume 11, Pages 47-55, https://doi.org/10.1016/j.jth.2018.09.009. EDITOR'S CHOICE

Brown CA, Lilford RJ. The stepped wedge trial design: a systematic review. BMC Medical Research Methodology. 2006;6:54. 
Craig P, Cooper C, Gunnell D, Haw S, Lawson K, Macintyre S, Ogilvie D, Petticrew M, Reeves B, Sutton $M$, Thompson S. Using natural experiments to evaluate population health interventions: new MRC guidance. Journal of epidemiology and community health. 2012;66(12):1182-1186. doi:10.1136/jech2011-200375.

Cross River Partnership. The walking tube in central London. A feasibility and implementation guide. London: Cross River Partnership, 2018.

https://crossriverpartnership.org/media/2018/07/WT Final electronic pages.pdf

Foster S, Karen Villanueva, Lisa Wood, Hayley Christian, Billie Giles-Corti. The impact of parents' fear of strangers and perceptions of informal social control on children's independent mobility. Health \& Place, Volume 26, 2014, Pages 60-68, https://doi.org/10.1016/i.healthplace.2013.11.006

Gao C, Abeysekera J. A systems perspective of slip and fall accidents on icy and snowy surfaces. Ergonomics, 47 (5) (2004), pp. 573-598.

Gard G , Glenn Berggård, Peter Rosander, Agneta Larsson. Pedestrians perceptions of community walking with anti-slip devices - An explorative case study. Journal of Transport \& Health, 2018, https://doi.org/10.1016/j.jth.2018.09.001.

Hillman M, Adams J, Whitelegg J. One false move... A study of children's independent mobility. London: Policy Studies Institute, 1990.

Hong J, Sila-Nowicka K, McArthur DP. Is the popularity of social networking services beneficial for public health? Focusing on active travel and BMI. Journal of Transport \& Health, 2018, Vol 11, https://doi.org/10.1016/j.jth.2018.09.003.

Keliikoa LB, Packard MY, Hansen Smith H, Kim IN, Akasaki KA, Stupplebeen DA. Evaluation of a community wayfinding signage project in Hawai'i: Perspectives of pedestrians and bicyclists. Journal of Transport \& Health, Volume 11, 2018, Pages 25-33, https://doi.org/10.1016/i.jth.2018.09.008.

Mackie H, Macmillan A, Witten K, Baas P, Field A, Smith M, Hosking J, King K, Sosene L, Woodward A. Te Ara Mua - Future Streets suburban street retrofit: A researcher-community-government codesign process and intervention outcomes panel. Journal of Transport \& Health, 2018,

O'Toole SE, Christie N. Deprivation and road traffic injury comparisons for 4-10 and 11-15 year-olds. Journal of Transport \& Health, 2018, Vol 11

Shekarrizfard M, Marie-France Valois, Scott Weichenthal, Mark S. Goldberg, Masoud Fallah-Shorshania, Laure Deville Cavellin, Dan Crouse, Marie-Elise Parent, Marianne Hatzopoulou. Investigating the effects of multiple exposure measures to traffic related air pollution on the risk of breast and prostate cancer. Journal of Transport \& Health, 2018, 11, 34-46.

Turner K, Ruth Jepson, Bradley MacDonald, Paul Kelly, Biggs H, Graham Baker Developing and refining a programme theory for understanding how twenty mile per hour speed limits impact health. Journal of Transport \& Health, 2018

Watkins SJ. The Transport and Health Study Group. J Transport and Health 2014;1(1):3-4. 